\title{
A “two-eyed seeing” approach to Indigenizing nursing curricula
}

\author{
Marti Harder ${ }^{1}$, Jessie Johnson ${ }^{* 2}$, Cathy MacDonald ${ }^{3}$, Andrea Ingstrup ${ }^{4}$, Marc J Piche ${ }^{5}$ \\ ${ }^{1}$ Vancouver Island University, Canada \\ ${ }^{2}$ Faculty of Nursing, University of Calgary Qatar, Qatar \\ ${ }^{3}$ Saint Francis Xavier University, Nova Scotia, Canada \\ ${ }^{4}$ First Nations Health Authority, Canada \\ ${ }^{5}$ School District 68 (Nanaimo Ladysmith), Canada
}

Received: October 17, 2018

DOI: $10.5430 /$ ijh.v5n1p23
Accepted: November 22, $2018 \quad$ Online Published: December 4, 2018

URL: https://doi.org/10.5430/ijh.v5n1p23

\begin{abstract}
Educational institutions, including schools of nursing, find themselves in significant times, as they work to Indigenize programs, and strive to repair and heal relationships with Indigenous peoples as recommended in the Truth and Reconciliation Commission of Canada (2015). Educators question where to begin the process, how such Indigenization should occur, and what the curricular end result should look like. In response, the authors considered many aspects from the literature, specific to nursing programs. The following themes were explored: partnering with community, cultural relevance, and faculty development. Through the utilization of a "two-eyed seeing" approach, institutional administrators need to partner with Indigenous Elders and community members to facilitate relationships required to provide the knowledge necessary to bring about change within educational programs. It is through such an approach that nursing curricula can be designed to be culturally safe and relevant for both Indigenous and non-Indigenous learners, and faculty can be supported in their growth and development in Indigenous knowledge. The authors propose that through "two-eyed seeing" and the integration of the Aboriginal Nurses Association of Canada (2009) core competencies, Indigenization of nursing curricula may ultimately move forward in a culturally reciprocal and respectful way.
\end{abstract}

Key Words: Indigenization, Nursing programs, Two-eyed seeing, Aboriginal, Education

\section{INTRODUCTION}

Universities in many countries are working towards the Indigenization of educational programs. In Canada, Indigenous peoples make up $4.9 \%$ of the population (totaling more than 1.6 million people), with the Indigenous population increasing four times faster than that of non-Indigenous people. ${ }^{[1]}$ However, few healthcare workers in Canada identify themselves as Indigenous, and this shortage has negatively affected health outcomes of Indigenous peoples. ${ }^{[2]}$ While there continues to be an underrepresentation of Indigenous students in nursing schools recruitment efforts are underway to promote these numbers. ${ }^{[3,4]}$ There continues to be a need to understand the factors affecting the retention of Indigenous students, ${ }^{[5]}$ and nurse educators and universities need to explore ways to foster success among Indigenous nursing students. High attrition rates, together with the shortage of Indigenous nurses, demand changes to nursing education curricula. ${ }^{[6]}$ Such changes must begin with a consideration of embedding Indigenous content into nursing programs.

*Correspondence: Jessie Johnson; Email: jessie.johnson1@ ucalgary.edu.qa; Address: Faculty of Nursing, University of Calgary Qatar, Qatar. 
The process of Indigenization of curricula can be difficult, and the authors begin with a discussion surrounding the critiques and challenges of this work. When changing curricula, "two-eyed seeing"[7] is required to bring together and honour differing views. It is through "two-eyed seeing", that the process of Indigenization can occur from a culturally safe approach. In reviewing the literature, several themes were identified in nursing curricula at the global level: the importance of partnering with community, faculty development, and cultural relevance. This narrative review of the literature was conducted through a constructionist framework. Constructionism, as defined by Papert, et al., ${ }^{[8]}$ views learning as building knowledge structures in a context whereby the learner is consciously engaged and considers that concepts can be understood by constructing them. From such an approach, the authors were able to examine the Indigenization of nursing curricula, and devise a series of recommendations towards this continued work in the future.

\section{DEFINITION OF INDIGENIZATION, AND WHY IS IT SO DIFFICULT?}

What does it mean to Indigenize curriculum, and how does it look within education programs? These questions have been asked, and grappled with, by many post-secondary institutions. Indigenizing program materials is more than understanding geographical, historical, economic, and sociopolitical contexts. ${ }^{[9]}$ To offer decolonized nursing education means engaging and questioning processes of colonialism that have occurred and are still occurring. ${ }^{[10]}$ As stated by Pete (2016), ${ }^{[11]}$ the process of Indigenization is more than simply adding content to educational programs: it is a transformation by decolonizing our collective work, and is a shared responsibility by Indigenous and non-Indigenous peoples. Bopp, Brown, and Robb (2016) ${ }^{[12]}$ further explain Indigenization as a process whereby knowledge is produced within the institution from an Indigenous perspective. Such definitions appear daunting, but through the use of documents such as the Truth and Reconciliation Commission of Canada (TRC) (2015), ${ }^{[13]}$ educational institutions are striving to move forward to create supportive spaces in which Indigenous people can succeed.

While the steps required to move forward may eventually become clearer, challenges remain, and a few are outlined here. There is a dearth of literature available on the process of Indigenization, and no one really knows what an Indigenized educational institution might look like. ${ }^{[14]}$ In essence, "we don't know what we don't know". Furthermore, it is well known that Indigenous identity does not mean the same to all people, nor is it consistent between communities. ${ }^{[15,16]}$ The danger in making curricular changes when very few In- digenous people have been consulted, is that it is easy for non-Indigenous peoples to generalize characteristics about the former, a practice known as pan-Indigenizing. ${ }^{[17]}$ It is important for the creation of ethical time and space to develop thorough, careful, and reflexive relationships prior to making changes within programs. Without such a cautious approach, the process of Indigenizing could evolve into ongoing colonialism (including power differentials), despite best intentions to the contrary. ${ }^{[18]}$ Because such ethical time and space is sometimes difficult to find in some academic programs (due to all hours being filled with curricular - required content), educators often do not have the time to devote to learning about Indigenization and how to go about making changes to their courses. ${ }^{[4]}$ For this reason, Indigenization may occur hurriedly, or without the mandatory careful consideration. The challenges of Indigenization lie in the method and spirit of integration of Indigenous knowledge into program curricula. One approach to address these difficulties is through "two-eyed seeing", which is described next.

\section{THE IMPORTANCE OF "TWO-EYED SEE- ING"}

Although Western and Indigenous knowledge systems differ in epistemological and ontological philosophies, ${ }^{[7,19-21]}$ blending principles from both can be beneficial to educate student nurses to provide holistic and culturally safe care. Indigenizing nursing curricula requires inclusion of Aboriginal perspectives and the valuing of Indigenous knowledge and epistemology. ${ }^{[22]}$ The authors recommend using a "two-eyed seeing" approach in curricula to heighten student nurses' knowledge relating to Indigenous people and to clarify understandings about the realities and diversities among Indigenous people to provide individualized healthcare. "Two-eyed seeing" (Sesatu'k Etuaptmunk), a concept first used by Elder Albert Marshall of Eskasoni First Nation, Nova Scotia, Canada, means that Indigenous knowledge and Western science are considered complementary knowledge forms; when integrated, these knowledge forms can advance the health and well-being of Indigenous people. ${ }^{[23]}$ Marshall asserts that "two-eyed seeing" is the need to learn (from one eye) the strengths of Indigenous traditional knowledge, and from the other eye, the strengths of Western scientific knowledge. Learning to use both eyes together will benefit both Western and Indigenous peoples' health and lives. A "two-eyed seeing" approach integrated in nursing curricula will assist in educating students about Indigenous people. It will further support the consideration of historical, economic, and socio-political contexts that shape Indigenous healthcare, access to healthcare, and healthcare deficits.

To Indigenize best practice, nursing faculty employing a 
"two-eye seeing" approach could facilitate the implementation of program changes with respectful approaches that are culturally safe for both Indigenous and non-Indigenous students. Such approaches must be emulated from nursing professors and staff preceptoring students. Indigenous knowledge and clinical examples may be embedded in simulation experiences, case studies, and presentations in curricula. However, it is important that Indigenous people not be essentialized in a "one-size-fits-all" health care approach. There is diversity amongst Indigenous communities and Nations. Essentialism ignores diversities and the unique experiences within groups, thus reinforcing the notion that only cultural characteristics shape socioeconomic, political, and health disadvantages. Essentialism overlooks the social determinates of Indigenous health that considers contexts of poverty, history (i.e., residential school, colonialism, assimilation), community infrastructure, resources, health behaviors, physical, and social environments that impact the health and health outcomes for Indigenous peoples. ${ }^{[24]}$ Thus, poor health and illnesses for Indigenous peoples are rooted in "deeper social structures and processes" (p. 1), ${ }^{[25]}$ and those may exist at the local community, national, or global levels. According to Browne (2007), ${ }^{[26]}$ lifestyle and personal choice of Indigenous people are often positioned as issues without examination of broader sociopolitical factors. Western healthcare discourses can also marginalize and stigmatize Indigenous people. ${ }^{[26]}$ It is, therefore, imperative that nursing curricula imbues appropriate discourses related to Indigenous people and contextualizes health status for Indigenous peoples regarding sociopolitical, historical, environmental, and economic factors. ${ }^{[27]}$ Doing so assists in decreasing labelling, laying blame for diseases rates, or for accessing healthcare late in disease trajectories. The authors recommend using a "two-eyed seeing" approach as a lens to Indigenizing nursing curricula, and the Aboriginal Nurses Association of Canada (ANAC) $(2009)^{[28]}$ core competencies as foundational in nursing curricula.

\section{BACKGROUND LITERATURE}

Upon review of the literature, a few themes were identified in regards to the Indigenization of nursing curricula at the global level: the importance of partnering with community, the need for faculty development, and the significance of culturally relevant curriculum. Each of these aspects will be discussed in the following section.

\subsection{Importance of partnering with community}

Although the notion of an emic versus etic perspective has long been associated within the research realm, it has a direct relation to universities who have programs that are geared toward Indigenous content. ${ }^{[29]}$ Universities need to position

Published by Sciedu Press themselves toward successful delivery of Indigenous content. However, this cannot be achieved without understanding Indigenous history. ${ }^{[18]}$ Furthermore, fostering relationships with communities and establishing ethical spaces for open dialogue is essential for the exchange of knowledge and learning the best way to provide healthcare to Indigenous people. ${ }^{[30]}$ Tantamount to the success of Indigenized curricula is the partnership of community stakeholders who have firsthand knowledge of the history related to Indigenous peoples. In order to achieve this, support must come from relevant sources: this could be Elders in the community or on reserve land, or Indigenous persons in government positions. ${ }^{[31]}$ Nursing faculty must learn from Indigenous people - the experts that can teach about their own culture, social determinants of health, and healthcare needs and outcomes. Mahara, Duncan, Whyte, and Browne (2011) ${ }^{[32]}$ conducted a study in which they strategized how to build a framework that included cultural competency and cultural safety in nursing education. Mahara et al., 2011 ${ }^{[32]}$ found that it was vital to enable Elders from the Indigenous community to work as partners in nursing programs. This was seen as a way forward in learning the "competencies related to Indigenous knowledge" (p. 5). ${ }^{[32]}$

Bopp et al. (2016) ${ }^{[12]}$ further discussed issues related to Indigenization within academic institutions and predicted that unless institutions partner with local Indigenous peoples and include them in decision-making processes, attempts to Indigenize education will fall short. Educational institutions must strive to maintain partnerships with key Indigenous stakeholders, and these can only be achieved if they are rooted within the whole of the institution. Once those partnerships exist, then individual programs (i.e., like nursing programs) can move towards successful pathways for both Indigenous and non-Indigenous students alike. ${ }^{[12]}$

\subsection{Need for faculty development}

All too often, faculty are asked to design courses within which they are required to embed Indigenous knowledge and health care practice within the nursing program; they often fall short because they do not possess enough knowledge to impart this information to students. Faculty are pivotal to providing a culturally safe environment for students as they navigate their way through nursing programs, but this cannot be achieved if faculty are not knowledgeable in how to do so. ${ }^{[33-36]}$ Moreover, it is of equal importance that faculty be afforded opportunities for professional development training to achieve this kind of knowledge. Indigenizing curricula results in student nurses being knowledgeable about Indigenous peoples' contexts, health, wellness, illness, and access to healthcare services; these components are also essential 
in implementing cultural safety in nursing practice. ${ }^{[28]}$ However, most faculty who teach within nursing programs do not have knowledge of Indigenous knowing, being, cultural background, and traditions which are seen as necessary to create a culturally safe environment. ${ }^{[31]}$

Faculty development should include support from the Indigenous community in order to validate, create accountability, and protect the situatedness of this knowledge. ${ }^{[18]}$ Professional development courses may be used toward the achievement of cultural competence, but equally important is the environment and the people within it that validate the very essence of the Indigenous story. Faculty development should include the skills necessary to enable them to relate to the soul of what it means to be Indigenous. This can be done with the help of pedagogy that involves narrative inquiry practices as a way forward to providing rich discussion in classrooms. ${ }^{[37]}$ In order to achieve this, faculty must have opportunity to learn about Indigenous history and customs related to practices. This could be done by enabling faculty to visit traditional or reserve lands and listening to the narratives of Indigenous persons. Faculty should also have an opportunity to immerse themselves in the Indigenous culture that they will pass along to students in the future. In some cases, Indigenous students' learning can be promoted through storytelling, ${ }^{[38]}$ thus faculty development should include skills needed to include this in classroom teaching. Recognizing that not everyone is equipped with enough knowledge and skills to tell stories, perhaps this can be done with the support of community Elders. ${ }^{[18]}$ Overall, success in student attainment of Indigenous knowledge comes from the faculty members who convey it and this can only be done if learning opportunities are available, and they take advantage of them.

\subsection{Significance of culturally relevant curricula}

Indigenization in the nursing curricula is culturally relevant to both Indigenous and non-Indigenous learners. The content and delivery of program materials needs to align with how students will process and apply theories to become competent practitioners. ${ }^{[9,39]}$ As mentioned earlier, current educational systems are predominantly posited in a Eurocentric (Western) worldview. ${ }^{[12]}$ Knowledge of colonial practices, treaties, acts, residential school, power imbalances, and intergenerational trauma has not been included in mainstream learning or dialogues. ${ }^{[12,40]}$ As Indigenization strategies are newly developing in educational institutions, those teaching in and attending nursing programs may lack awareness and understanding of the context of historical atrocities and ongoing legacies experienced by Indigenous peoples.

Setting students up for success, through Indigenization, is complex as institutions embark on a journey toward a shift from current epistemological and ontological institutional practices. Each learner is challenged in their own way, and attempts are made to bridge the knowledge gaps for those not informed of Indigenous ways of knowing and being. [39] Similarly, sensitivity to the acculturation of Indigenous students must occur, and care must be taken to prevent assumptions that all Aboriginal peoples are aware of their ancestors' history, while still eliminating barriers to holistically support Indigenous learners. ${ }^{[41]}$ The TRC $(2015)^{[13]}$ addresses disparities in health outcomes recommending that society "... close the gaps in health outcomes between aboriginal and nonaboriginal peoples" (action 19, pp. 2-3). Understanding individual biases, assumptions, and beliefs brings awareness of the influence of cultural bias on practitioners' care for Indigenous peoples and how providers have an impact on a person's experience with health systems. ${ }^{[39]}$ Implementing learning to support culturally safe care is commonly addressed in the literature and a further call to action. ${ }^{[9,12,13,39-41]}$ As current practices and learning applications in the literature are explored, it becomes more obvious that nursing programs need to be tailored to be culturally responsive to students, faculty, and the Indigenous communities within which they work and serve.

\section{Conclusion}

Embedding Indigenous content in a meaningful way into nursing curriculum is multifaceted. The authors discovered many aspects to consider in this process, and the themes of partnering with community, faculty development, and cultural relevance were explored in this article. During this historical time of repair and healing, we are called to action by the TRC (2015) ${ }^{[13]}$ to eradicate health care disparities for Indigenous peoples. Nursing educators are to provide nonIndigenous faculty and learners with the supports needed to be culturally safe. As well, Indigenous nursing students need to be supported in their learning, thus promoting increased enrolment in nursing education. As we move away from colonized epistemological and ontological philosophies to create spaces for Indigenous and non-Indigenous learners, we rely on our Indigenous Elders to guide and inform healing practices that will enhance nursing education and empower nurses to be responsive to the diversity of health care needs. Similarly, academic institutions offering nursing education need to become more attuned with Indigenous communities residing in the ancestral lands where they are situated, and explore how to foster relationships in order to recruit and retain Indigenous students into nursing programs. "Two-eyed seeing" ${ }^{[7]}$ embraces a strength-based approach which capitalizes on the best of Indigenous and Western epistemologies with mutual reciprocity and respect, and it is through this 
approach that the authors believe Indigenization in nursing curricula may be realized.

\section{Recommendations}

Recommendations for Indigenizing Nursing Curricula include:

- Implement a "two-eyed seeing" approach

- Involve Elders and Indigenous community members in curricula development, implementation, and evaluation

- Use ANAC (2009) core competencies in curricula development

- Use Truth and Reconciliation Commission of Canada:
Call to Action (2015) report in curricula development

- Nursing professors, clinical educators, and staff preceptoring nursing students must respectfully educate student nurses about Indigenous peoples' health using culturally safe examples in class and practice

- Have Indigenous nurses, Elders, and community members as guest speakers in classes

- Implement assignments in nursing curricula that embody Indigenous knowledge and teachings in case studies, presentations, and simulation

\section{CONFLicts OF INTEREST Disclosure}

The authors declare no conflicts of interest.

\section{REFERENCES}

[1] Statistics Canada. Aboriginal peoples in Canada: Key results from the 2016 census. 2016. Available from: http://www. statcan.gc .ca/daily-quotidien/171025/dq171025a-eng.htm

[2] King M, Smith A, Gracey M. Indigenous health part 2: The underlying causes of the health gap. The Lancet. 2009; 374: 76-85. https://doi.org/10.1016/S0140-6736(09)60827-8

[3] Burruss N, Popkess A. The diverse learning needs of students. In D. Billings \& J. Halstead (Eds.). Teaching in nursing: A guide for faculty (pp. 15-33). St. Louis: Elsevier Saunders. 2012.

[4] Kulig J, Lamb M, Solowoniuk J, et al. Nurturing a dream: The support program for Aboriginal nursing students. First Nations Perspectives. 2010; 3(1): 89-106.

[5] Canadian Nurses Association. Aboriginal health nursing and Aboriginal health: Charting policy direction for nursing in Canada. 2014. Available from: https://www.cnaaiic.ca/ /media/cn a/page-content/pdf-en/aboriginal-health-nursing-a nd-aboriginal-health_charting-policy-direction-for -nursing-in-canada.pdf?la=en

[6] Slatyer S, Cramer J, Pugh J, et al. Barriers and enablers to retention of Aboriginal diploma of nursing students in Western Australia: An exploratory descriptive study. Nurse Education Today. 2016; 42: 1722. PMid:27237347. https://doi.org/10.1016/j.nedt. 2016. 03.026

[7] Martin D. Two-eyed seeing: A framework for understanding Indigenous and non-Indigenous approaches to Indigenous health research. Canadian Journal of Nursing Research. 2012; 44(2): 20-42. PMid:22894005.

[8] Papert S, Harel I. Situating constructionism. In S. Papert \& I. Harel, Constructionism, (ch. 2). New York: Ablex Publishing Corporation; 1991.

[9] Moffitt P. Mobilizing decolonized nursing education at Aurora College: Historical and current considerations. The Northern Review. 2016; 43: 67-81.

[10] Smith L. Decolonizing methodologies: Research and Indigenous peoples (2nd ed.). New York: Palgrave Macmillan; 2012.

[11] Pete S. 100 ways: Indigenizing and decolonizing academic programs. Aboriginal Policy Studies. 2016; 6(1): 81-89. https ://doi.org/ 10.5663/aps.v6i1.27455

[12] Bopp M, Brown L, Robb J. Reconciliation within the academy: Why is Indigenization so difficult? The Northern Review. 2016; 43: 1-10.
[13] Winnipeg MB. Truth and Reconciliation Commission of Canada (TRC). Truth and reconciliation commission of Canada calls to action. 2015.

[14] MacDonald M. Indigenizing the academy. University Affairs. 2016 Available from: http://www.universityaffairs.ca/feature s/feature-article/indigenizing-the-academy/

[15] Retzlaff S. What's in a name? The politics of labeling and Native identity constructions. Canadian Journal of Native Studies. 2005; 25(2): 609-626.

[16] United Nations. United Nations declaration on the rights of Indigenous peoples. 2006. Available from: https: //www.un.org/development/desa/indigenouspeoples/de claration-on-the-rights-of-indigenous-peoples.html

[17] Greenwood M, de Leeuw S, Ngaroimata Fraser T. When the politics of inclusivity become exploitative: A reflective commentary on Indigenous peoples, indigeneity, and the academy. Canadian Journal of Native Education. 2008; 31(1): 198-207.

[18] FitzMaurice K. Transgressing the boundaries of Native studies: Traces of "white paper" policy in academic patterns of Indigenization. The Canadian Journal of Native Studies. 2011; 31(2): 63-76.

[19] Battiste M. Reclaiming indigenous voice and vision. Vancouver, BC, Canada: UBC Press; 2000.

[20] Dion Stout M. Ascribed health and wellness, Atikowisi miýw-ayawin, to achieved health and wellness, Kaskitamasowin miýw-ayawin: Shifting the paradigm. Canadian Journal of Nursing Research. 2012; 44(2): 11-14.

[21] Loppie C. Learning from the grandmothers: Incorporating Indigenous principles into qualitative research. Qualitative Health Research. 2007; 17(2): 276-284. PMid:17220397. https://doi.org/10.1 $177 / 1049732306297905$

[22] Kovach M. Emerging from the margins: Indigenous methodologies. Toronto, ON, Canada: Canadian Scholars' Press/Women's Press; 2005.

[23] Marshall A. Two eyed seeing. 2007. Available from: http://www. turtleisland.org/culture/twoeyed.htm

[24] Loppie-Reading C, Wien F. Health inequalities and social determinants of Aboriginal peoples' health. Prince George, BC, Canada: National Collaborating Centre for Aboriginal Health. 2009. 
[25] Czyzewski K. Colonialism as a Broader Social Determinant of Health. The International Indigenous Policy Journal. 2011; 2(1): 1-16. https://doi.org/10.18584/iipj.2011.2.1.5

[26] Browne AJ. Clinical encounters between nurses and First Nations women in a Western Canadian hospital. Social Science \& Medicine. 2007; 64(10): 2165-2176. PMid:17395350. https ://doi .org/10 $.1016 /$ j.socscimed.2007.02.006

[27] MacDonald C, Martin-Misener R, Steenbeek A, et al. Honoring stories: Mi'kmaq women's experiences with pap smear screening in Eastern Canada. Canadian Journal of Nursing Research. 2015; 47(1): 72-96. PMid:29509451. https://doi.org/10.1177/08445621 1504700106

[28] Aboriginal Nurses Association of Canada (ANAC). Cultural competence and cultural safety in First Nations, Inuit and Métis nursing education: An integrated review of the literature. 2009. Available from: https://www.uleth.ca/dspace/bitstream/ handle/10133/720/An_Integrated_Review_of_the_Liter ature.pdf? sequence $=1$

[29] Bilic S. Researching minority culture woman's standpoint and experiences of rights. CSAA 2011 Conference Proceedings: Cultural ReOrientations and Comparative Colonialities (pp. 140-160). 2012. Available from: http://search.ror.unisa.edu.au/record/U NISA_ALMA11143294360001831

[30] Ermine W. Ethical space of engagement. Indigenous Law Journal. 2007; 6(1): 193-203

[31] Milne T, Creedy D, West R. Integrated systematic review on educational strategies that promote academic success and resilience in undergraduate Indigenous students. Nursing Education Today. 2016; 36: 387-394. PMid:26521033. https ://doi.org/10.1016/j.ne dt. 2015.10 .008

[32] Mahara M, Duncan S, Whyte N, et al. It takes a community to raise a nurse: Educating for culturally safe practice with Aboriginal peoples. International Journal of Nursing Education Scholarship. 2011; 8(1): 1-13. https : //doi .org/10.2202/1548-923X . 2208

[33] Craven R, Dillon A. Seeding success in Indigenous Australian higher education: Indigenous Australian students' participation in higher ed- ucation and potential ways forward. In R. Craven \& J. Mooney (Ed.) Seeding Success in Indigenous Australian Higher Education (Diversity in Higher Education, Volume 14), pp. 3-27. Bingley: Emerald Book Publishing Limited; 2013.

[34] Hall M, Rata A, Adds P. He manu hou: The transition of Maori students into Maori studies. The International Indigenous Policy Journal. 2013; 4(4): 1-19. https://doi.org/10.18584/iipj .2013.4.4 .7

[35] Department of Health. Aboriginal and Torres Strait islander health curriculum framework. Commonwealth of Australia: Canberra, Australia; 2015.

[36] Thackrah R, Thompson S. Confronting uncomfortable truths: Receptivity and resistance to Aboriginal content in midwifery education. Contemporary Nurse. 2013; 46: 113-122. PMid:24716769. https://doi.org/10.5172/conu.2013.46.1.113

[37] Haydon G, van der Riet P. Narrative inquiry: A relational research methodology suitable to explore narratives of health and illness. Nordic Journal of Nursing Research. 2017; 37(2): 85-89. https : //doi .org/10.1177/2057158516675217

[38] Curran V, Solberg S, LeFort S, et al. A responsive evaluation of an Aboriginal nursing education access program. Nurse Educator. 2008; 33(1): 13-17. PMid:18091465. https ://doi.org/10.109 7/01. NNE.0000299496.23119.68

[39] Shah C, Reeves A. The Aboriginal cultural safety initiative: An innovative health sciences curriculum in Ontario colleges and universities. International Journal of Indigenous Health. 2015; 10(2): 117-131. https://doi.org/10.18357/ijih.102201514388

[40] Smith D. Reconciliation and the academy: Experience at a small institution in northern Manitoba. Canadian Journal of Educational Administration and Policy. 2017; 183: 61-81.

[41] Usher K, Miller M, Turale S, et al. Meeting the challenges of recruitment and retention of Indigenous people into nursing: Outcomes of the Indigenous nurse education working group. Collegian. 2005; 12(3): 27-31. https ://doi .org/10.1016/S1322-7 696 (08) 60498-9 